\title{
Factors Associated with Rising Trend in Teenage Pregnancy within the West Gonja Municipality of the Savannah Region of Ghana
}

\author{
Josiah Nang-Bayi1 ${ }^{*}$, Saatiero Frenk Wie1, Vincent Siepaal1, Paul Kuufira1', Edmund Muonir Der²,3
}

${ }^{1}$ School of Medicine, University for Development Studies, Tamale, Ghana

${ }^{2}$ Department of Pathology, School of Medicine, University for Development Studies, Tamale, Ghana

${ }^{3}$ Department of Pathology, Tamale Teaching Hospital, Tamale, Ghana

Email: *josynangbayi@gmail.com

How to cite this paper: Nang-Bayi, J., Wie, S.F., Siepaal, V., Kuufira, P. and Der, E.M. (2021) Factors Associated with Rising Trend in Teenage Pregnancy within the West Gonja Municipality of the Savannah Region of Ghana. Open Journal of Obstetrics and Gynecology, 11, 1273-1290.

https://doi.org/10.4236/ojog.2021.119119

Received: August 17, 2021

Accepted: September 27, 2021

Published: September 30, 2021

Copyright $\odot 2021$ by author(s) and Scientific Research Publishing Inc. This work is licensed under the Creative Commons Attribution International License (CC BY 4.0).

http://creativecommons.org/licenses/by/4.0/

(c) (i) Open Access

\begin{abstract}
Background: Teenage pregnancy is a major public health problem worldwide, also in northern Ghana. The aim of this study was to identify factors contributing to the rising trend in teenage pregnancy and the resultant effects. Materials and Methods: This was a cross-sectional study using a quasi-structured questionnaire on 60 pregnant teenagers. Demographic data and factors associated with teenage pregnancy were collected/analyzed. Results: The mean age of respondents was $17.25 \pm 1.93$ years. Junior high school students or graduates accounted for $55 \%$. About $35 \%$ of participants dropped out of school due to pregnancy. The following factors were identified to be associated with teenage pregnancy: low socio-economic status, no/less sexualand reproductive-communication with parents, low level of education, no sexual and reproductive health knowledge, and unsafe sexual behaviours. The consequences of teenage pregnancy identified were: truncation of the girls' education, psychological trauma, and worsening family relationships. The following health consequences were identified; anaemia in pregnancy, severe malaria, hypertension in pregnancy, and prolonged labour. Conclusion: The following factors may account for the rising trend in teenage pregnancy in this area: family-related problem, sociocultural factors, low education level, and the lack of adequate knowledge on reproductive health. Teenage pregnancy caused several problems in themselves and their family members.
\end{abstract}

\section{Keywords}

Teenage, Pregnancy, Rising Trend, Factors

\section{Introduction}

Teenage pregnancy in the recent past has been a major public health issue, espe- 
cially in developing countries [1]. Globally, 1 in 6 pregnant women is aged 10 to 19 years [2]. Approximately, one-tenth of all births are by females aged 20 years or below, and the great majority of these births were recorded in developing countries [2]. In both the developed and developing countries, teenage birth rate in 2014 was quoted by the World Health Organisation as 49 per 1000 girls aged 15 to 19 years [3].

According to the WHO [4], the term "adolescent" is often used synonymously with "teenager". In this sense, “adolescent/teenage pregnancy" means pregnancy in a female aged 10 - 19 years [4]. WHO further classified adolescents into early (10 - 14 years) and late (15 - 19 years) [4]. In Ghana, adolescent or teenager is similarly defined as a person within the age range of 10 - 19 years. Teenage pregnancy, in Ghana, is therefore defined as getting pregnant within the teenage or adolescent period.

Every year, an estimated 21 million girls aged 15 - 19 years in developing countries become pregnant and approximately 12 million of them give birth [5]. At least 777,000 births occur to adolescent girls younger than 15 years [5].

In Ghana, teenagers represent $22.4 \%$ of the total population, with high rates of teenage pregnancies [6]. About $30.0 \%$ of all births registered in Ghana in the year 2014, were by teenage mothers, of which the great majority, $14.0 \%$, were late adolescents [6].

Several factors have been identified to be associated with teenage pregnancy in Africa [7]. For instance, a study done in Egypt discovered that levels of sexual activity, general sex education and access to affordable contraceptive were among these factors [7]. Similarly, in Ghana, early marriage, lack of education, peer influence, non-use or incorrect use of contraceptives, poverty, influence of alcohol and drug use, low self-esteem and exposure to family violence or abuse, were that factors identified to account for the rising trend in teenage pregnancy [8]. Furthermore, in Ghana, teenage pregnancies and deliveries are linked to increased risk factors of stillbirths and neonatal deaths [6].

The socio-economic effects of teenage pregnancy have been highlighted as; truncated academic and intellectual development, low levels of employable skills, and consequently low socio-economic status [1] [6] [9]. For this reason, prevention of child marriage and reduction of teenage pregnancy has long been the focus of several governmental and non-governmental organizations.

\section{Problem Statement}

Teenage pregnancy is linked to disadvantaged socio-economic situations [1]. It is considered to be a serious public health issue worldwide [10]. In low and middle-income countries, there is a rising trend in teenage pregnancy and about 21 million girls in late adolescents are estimated to get pregnant and about 16 million give birth annually [11] [12]. It is reported that the highest teenage pregnancy rates are reported in Africa [3]. In 2014, Ghana Statistical Service reported that about $14.0 \%$ of adolescent girls in late adolescence started childbearing with 
about $11.0 \%$ live birth rate [13].

Adolescent pregnancy is associated with a higher risk of maternal and neonatal complications; such as hypertensive in pregnancy, unsafe abortion, urinary tract infections, and premature rupture of the foetal membranes, anaemia and obstructed labour resulting in increased caesarean section rates [7] [8] [12] [14]. Several studies have shown that the high level of maternal and perinatal morbidity and mortality can be reduced by lowering the high rate of adolescent pregnancy in developing countries [8].

Data from the West Gonja Municipal Health Directorate covering the period 2016 to 2020, indicates a rising trend in the prevalence of teenage pregnancy in the municipality, despite several social interventions that curbing the situation. This study conducted within the Municipality therefore seeks to assess the factors accounting for this trend.

\section{Specific Objectives}

1) To identify the factors associated with the observed trends in teenage pregnancy in the West Gonja Municipality.

2) To examine how these factors interconnect and affect the rising trend of teenage pregnancy in the West Gonja Municipality.

3) To examine how the behaviour of relatives and partners affect the teenage mothers.

4) To examine how teenage pregnancy affects the educational progression of teenage mothers in the West Gonja Municipality.

\section{Methodology/Materials and Methods}

\subsection{Study Area}

The Study Area Was the West Gonja Municipal Assembly

The West Gonja Municipal is one of the 260 Metropolitan, Municipal and District Assemblies (MMDAs) in Ghana, and forms part of the 7 MMDAs in the Savannah Region. With its administrative capital at Damongo, it was established in 2004 by a new legislative instrument (L.I.1775).

The West Gonja Municipality health directorate has five sub-districts, namely: Busunu, Laribanga, DASS, Damongo, and Canteen sub-districts. There are twenty-six health centers distributed in the sub-districts. The population of the Municipal according to 2018 population and housing census stands at 50,504 with 24,830 males and 25,674 females. (Health Directorate Census, 2018) West Gonja Municipal is located to the west of Tamale, the Northern Regional capital of Ghana and it lays within longitude $10^{\circ} 5^{\prime} 11^{\prime} \mathrm{W}$ and $20^{\circ} 58^{\prime} 1 " \mathrm{~W}$ and latitude $80^{\circ} 32^{\prime} 1^{\prime \prime} \mathrm{N}$ and $100^{\circ} 2^{\prime} 1 " \mathrm{~N}$. This Municipality was used as study area for previous studies on Stillbirths at the West Gonja hospital in northern Ghana [15].

\subsection{Study Type/Design}

This Was a Cross-Sectional Study

A cross-sectional study is an observational study that analyzes data from a pop- 
ulation, or a representative subset, at a specific point in time. This study design is cheap, fast and allows the study of multiple factors at the same time. It is also perfect for research situations where it is more convenient to use a sample and the make an inference to a whole population.

\subsection{Study Population}

The study population consisted of teenagers, aged 10 to 19 years, who were either pregnant or had given birth at the time of the study, and were residents of the five sub-districts of the West Gonja Municipality at the time of the study.

According to Fraenkel et al., [16] population refers to the group of interest to the researcher, "the group the researcher would like to generalize the result of the research to". Bordens et al., [17] further added that a population includes all people in a definable group. This means that a population can be of any size and that it will have at least one unique characteristic that makes it outstanding.

\subsection{Sampling Techniques}

The study involved a cluster sampling, followed by convenience sampling within the cluster. The five sub-districts formed the clusters for study.

Convenience sampling was employed to select pregnant teenagers and teenage mothers during antenatal care and Outpatient department (OPD) visits at the time of data collection. The choice of the sub-districts was based on factors such as socioeconomic status, background characteristics and homogeneity.

\subsection{Sample Size Determination}

The sample size for this study was determined according to Fink [18] and Sarantokos [19] principles, using the equation:

$$
n=\left[Z_{a / 2}\right]^{2}[\hat{p} \hat{q}] \div E^{2}
$$

where, $n=$ Sample size.

$$
\begin{aligned}
& \hat{p}=\text { population proportion }=0.04 . \\
& \qquad \hat{q}=1-\hat{p}=1-0.04=0.96 \\
& Z_{a / 2}=\text { Critical value }=1.96 . \\
& E=\text { Margin of error }=1-\text { Confidence Level }=0.05 \\
& \text { Sample size }=\frac{1.96^{2} \times 0.04 \times 0.96}{0.05^{2}}=60 \text { Participants }
\end{aligned}
$$

The desired confidence level was $95 \%$, with a critical value of 1.96 , significance level of $5 \%$ and population proportion of 0.04 was used in arriving at the study participants.

\subsection{Data Collection Tools/Instruments}

Data collection was done using a quasi-structured questionnaire. A questionnaire is a research instrument consisting of a series of questions and other prompts for the purpose of gathering information from respondents. Although 
they are often designed for statistical analysis of the responses, this is not always the case. The questionnaire was invented by Sir Francis Galton (1822-1911). Questionnaires have advantages over some other types of surveys in that they are cheap, do not require as much effort from the questioner as verbal or telephone surveys, and often have standardized answers that make it simple to compile data $[20]$.

\subsection{Pilot Study and Pre-Testing}

A pilot study or pretest was carried out after the research assistants have been trained in data collection. It was done within the West Gonja Municipal where the adolescents have similar characteristics as those in the study area. After the pretesting, the questionnaires were reviewed and the necessary corrections were made before data was collected. The pretesting helped to clarify the adequacy of the questions, estimate the approximate time for each questionnaire and help make the necessary corrections for the actual study.

\subsection{Data Collection Techniques and Analysis}

Quasi-structured questionnaires were used to interview adolescents to gather data. The questionnaires were read and filled for respondents who could not read and write, with translation in the local language. For participants who could read and write, the questionnaires were given to them to answer in private, with guidance where needed. The consent of the participants was obtained before questionnaires were administered. Participants signed or thumb-printed on a well written consent form, after the study was explained to them, as consent to participate voluntarily. In situations where guardians were present for respondents who are below 18 years, the guardians signed before questionnaires were administered.

Descriptive statistics was used to describe the factors that influence adolescent pregnancy by summarizing them into percentages, proportions and frequencies. Mean and standard deviation were calculated for age. Figures were presented in tables. Data was analyzed using Stata version 13, SPSS and Microsoft Excel. Chi-square test was used to measure association between the outcome and predictor variables. A P-value of less than 0.05 indicated a significant association between the variables.

Data entry was done using Statistical Package for Social Sciences. To calculate the economic status of the respondents' parents or guardian using their assets, Principal Component Analysis (PCA) method was used. The PCA helps to estimate the wealth levels using the asset of the persons as wealth indicator [21] [22] [23] [24]. Assets such as television, washing machine, sowing machine, refrigerator, mobile phones, car, houses and farms were used as a measure of the economic status of the respondents.

\subsection{Quality Control, Validity, Reliability}

Good data quality assures completeness, consistency, validity and reliability of 
information generated. Since adolescent reproductive health issues are sensitive and adolescents are vulnerable, professionalism and skill were employed during data collection. For this reason, all personnel involved in the data collection were sensitized appropriately.

Training topics included ethical interaction with participants and respect for their privacy, method of data collection, the study area and the objectives of the research work. The principal investigators monitored activities of all personnel to ensure proper data collection.

\section{Results}

\subsection{Socio-Demographic Information of Participants}

A total of 60 participants were enrolled in this study. Their ages ranged from 11 to 19 years, with a mean age of $17.25 \pm 1.93$ years, and a modal age group of 15 to 19 years (late adolescence) (Table 1). A total of 26 (43.3\%) participants were dating but not married, followed by those who were single (Table 1). At the time of data collection, 44 (73.3\%) participants had stopped schooling. A little above half, $33(55.0 \%)$, of the 60 participants were junior high students or graduates, followed by $11(18.3 \%)$ participants who were senior high school students (Table 1).

Majority, 42 (70.0\%), of the participants were Muslims (Table 1). Some, 28 (46.7\%) of the respondents were Gonjas by tribe, followed by Dagaabas, 9 (15.0\%) and Frafras, 7 (11.7\%) (Table 1). Approximately, one third of the respondents were residents of the Damongo township (Canteen, Damongo and DASS sub-districts) (Table 1).

\subsection{Sexual Behaviour}

The age at which participants were initiated into sexual activity ranges from 11 to 19 years, with mean age of $14.3 \pm 2.7$ years. Out of the total of 60 participants, $39(65 \%)$ were initiated by their boyfriends, while a little above one sixth, 7 (11.7\%) were initiated by other friends (Table 2).

On the mode of initiation, 33 (55.0\%) participants had consensual sex, followed by those who were coerced or persuaded into the act, 18 (30.0\%). Only 1 (1.7\%) respondent engaged in the act under the influence of alcohol (Table 2). A total of $36(60 \%)$ used contraceptives. Half, (50.0\%), of this number used the male condom as their method of contraction, followed by those who used emergency contraceptives, 10 (27.8\%) (Table 2).

\subsection{Sexual and Reproductive Health Services (SRHs)}

A total of $40(66.7 \%)$ of the 60 participants had knowledge on sexual and reproductive services, while the remaining 20 (33.3\%) said they did not know about such services. Out of the 40, $25(62.5 \%)$ respondents first had the information through electronic media, while $5(12.5 \%)$ said they first heard about it through social media. Furthermore, majority 29 (72.5\%) of these 40 participants reported 
Table 1. Socio-Demographic information of participants.

\begin{tabular}{|c|c|c|c|}
\hline Study Parameter & Frequency (n) & Percentage (\%) & p-values \\
\hline \multicolumn{4}{|l|}{ Age } \\
\hline Early adolescence (10 - 14) & 5 & 8.33 & \\
\hline Late adolescence (15 - 19) & 55 & 91.7 & \\
\hline Mean & $17.3 \pm 1.93$ & & \\
\hline \multicolumn{4}{|l|}{ Marital status } \\
\hline Single & 20 & 33.3 & \\
\hline Dating & 26 & 43.3 & \\
\hline Married & 14 & 23.3 & \\
\hline Divorce & 0 & 0 & \\
\hline Currently schooling & & & 0.0003 \\
\hline Yes & 16 & 26.7 & \\
\hline No & 44 & 73.3 & \\
\hline \multicolumn{4}{|l|}{ Level of education } \\
\hline No formal education & 5 & 8.3 & \\
\hline Primary & 10 & 16.7 & \\
\hline Junior High School & 33 & 55.0 & \\
\hline Senior High School & 11 & 18.3 & \\
\hline College/Tertiary & 1 & 1.7 & \\
\hline \multicolumn{4}{|l|}{ Religious affiliation } \\
\hline Christian & 17 & 28.3 & \\
\hline Muslim & 42 & 70.0 & \\
\hline Other & 1 & 1.7 & \\
\hline \multicolumn{4}{|l|}{ Ethnic background } \\
\hline Dagaaba & 9 & 15.0 & \\
\hline Frafra & 7 & 11.7 & \\
\hline Dagomba & 6 & 10.0 & \\
\hline Gonja & 28 & 46.7 & \\
\hline Others & 10 & 16.7 & \\
\hline \multicolumn{4}{|l|}{ Place of residence } \\
\hline DASS sub & 6 & 10.0 & \\
\hline Damongo Sub & 5 & 8.3 & \\
\hline Busunu Sub & 18 & 30.0 & \\
\hline Canteen & 22 & 36.7 & \\
\hline Laribanga Sub & 9 & 15.0 & \\
\hline
\end{tabular}

${ }^{*}$ Confidence level $=95 \%$; Critical value $=1.96$; and Level of significance $=0.05$. 
Table 2. Sexual behaviour.

\begin{tabular}{|c|c|c|c|}
\hline Last Time Had Sex & Frequency (n) & Percentage (\%) & p-values \\
\hline Less than a week & 24 & 40.0 & \\
\hline Less than a month & 18 & 30.0 & \\
\hline More than a month & 18 & 30.0 & \\
\hline \multicolumn{4}{|l|}{ Age of first sex $(n=51)$} \\
\hline Mean & $14.3 \pm 2.7$ & & \\
\hline Range (minimum-maximum) & $11-19$ & & \\
\hline \multicolumn{4}{|l|}{ Who initiated } \\
\hline Boyfriend & 39 & 65.0 & \\
\hline Husband & 3 & 5.0 & \\
\hline Sibling & 2 & 3.3 & \\
\hline Friend & 7 & 11.7 & \\
\hline Others & 9 & 15.0 & \\
\hline \multicolumn{4}{|l|}{ How were you initiated $(n=60)$} \\
\hline Consensual sex & 33 & 55.0 & \\
\hline Persuaded & 18 & 30.0 & \\
\hline Was under the influence of alcohol/drugs & 1 & 1.7 & \\
\hline Don't know what happened & 8 & 13.3 & \\
\hline \multicolumn{4}{|l|}{ Form of protection $(n=36)$} \\
\hline Condom & 18 & 50.0 & \\
\hline Normal contraceptives & 6 & 6.7 & \\
\hline Emergency contraceptives & 10 & 27.8 & \\
\hline Others & 2 & 5.6 & \\
\hline \multicolumn{4}{|l|}{ Age of partner $(n=58)$} \\
\hline Mean & $18.6( \pm 5.5 \mathrm{SD})$ & & \\
\hline Range (minimum-maximum) & $10-30$ & & \\
\hline $\begin{array}{l}\text { Currently in a relationship } \\
(\mathrm{n}=60)\end{array}$ & & & 0.0003 \\
\hline Yes & 44 & 73.3 & \\
\hline No & 16 & 26.7 & \\
\hline \multicolumn{4}{|l|}{$\begin{array}{l}\text { Number of sexual partners } \\
(n=60)\end{array}$} \\
\hline One sexual partner & 52 & 86.7 & \\
\hline Two sexual partners & 5 & 8.3 & \\
\hline Three sexual partners & 3 & 5.0 & \\
\hline $\begin{array}{l}\text { Currently use protection with } \\
\text { partner }(\mathrm{n}=52)\end{array}$ & & & 0.0056 \\
\hline Yes & 16 & 30.8 & \\
\hline No & 36 & 69.2 & \\
\hline
\end{tabular}

${ }^{*}$ Confidence level $=95 \%$; Critical value $=1.96$; and Level of significance $=0.05$. 
never visiting a SRHS center (Table 3 ).

\subsection{Family Related Issues}

A total of $39(65.0 \%)$ participants reported both parents being alive, while 21 (35.0\%) participants reported the death of at least one parent. Out of the 39, 4 (10.3\%) participants had their parents separated (Table 4).

Less than a third, $16(26.7 \%)$ of the respondents reported ease of sexual communication with their mothers while only 2 (3.3\%) reported such ease of communication with their fathers (Table 4).

About one third of the participants had elder sisters that have had teenage pregnancy in the past, and few of them said that this occurrence had effect on their pregnancy state (Table 4).

\subsection{Socio-Economic Status}

Majority, 42 (70.0\%), of the participants were in the middle-income class, compared to $18(30.0 \%)$ in the low-income group. No respondent belonged to the high-income class.

\subsection{Pregnancy and Age Relation}

The great majority, 47 (78.3\%), of the participants were primigravida, whilst 13 (21.7\%) have had a total of 2 pregnancies, including the current pregnancy (Table 5).

The mean age at which participants had their first pregnancy was $15.97 \pm 2.5$, with a great majority, $54(90.0 \%)$, of participants falling within the age range 15 to 19 years (Table 5 ).

The age range of the male partners was 15 to 31 years, with mean age of $16 \pm$ 2.7 years (Table 5 ).

Table 3. Sexual and reproductive health services.

\begin{tabular}{lccc}
\hline \multicolumn{1}{c}{ Study Parameter } & Frequency (n) & Percentage (\%) & p-values \\
\hline $\begin{array}{l}\text { Ever heard of sexual and } \\
\text { reproductive health service }\end{array}$ & 40 & & \\
Yes & 20 & 66.7 & 0.0098 \\
No & & 33.3 & \\
First heard about it & 21 & & \\
Television & 4 & 62.5 & \\
Radio & 5 & 10.0 & \\
Social Media & 10 & 12.5 & \\
Others & & 25.0 & \\
Ever visited a SRHS facility & 11 & & \\
Yes & 29 & 27.5 & \\
No & & 72.5 & \\
${ }^{*}$ Confidence level = 95\%; Critical value $=1.96$; and Level of significance $=0.05$. &
\end{tabular}


Table 4. Family related issues.

\begin{tabular}{|c|c|c|c|}
\hline Study Parameter & Frequency (n) & Percentages (\%) & p-values \\
\hline \multicolumn{4}{|l|}{ Both parents still live } \\
\hline Yes & 39 & 65.0 & 0.0201 \\
\hline No & 21 & 35.0 & \\
\hline \multicolumn{4}{|l|}{ If they are still married } \\
\hline Yes & 35 & 58.3 & $<0.0001$ \\
\hline No & 4 & 6.7 & \\
\hline $\begin{array}{l}\text { Ease of sexual communication } \\
\text { with father }\end{array}$ & & & $<0.0001$ \\
\hline Yes & 2 & 3.3 & \\
\hline No & 58 & 96.7 & \\
\hline $\begin{array}{l}\text { Ease of sexual communication } \\
\text { with mother }\end{array}$ & & & 0.0003 \\
\hline Yes & 16 & 26.7 & \\
\hline No & 44 & 73.3 & \\
\hline Sister gave birth at an early age & & & 0.0098 \\
\hline Yes & 20 & 33.3 & \\
\hline No & 40 & 66.7 & \\
\hline $\begin{array}{l}\text { Any influence on your current } \\
\text { state }\end{array}$ & & & 0.0736 \\
\hline Yes & 6 & 30.0 & \\
\hline No & 14 & 70.0 & \\
\hline
\end{tabular}

${ }^{*}$ Confidence level $=95 \%$; Critical value $=1.96$; and Level of significance $=0.05$.

Table 5. Pregnancy and age relation.

\begin{tabular}{lccc}
\hline \multicolumn{1}{c}{ Study Parameter } & Frequency (n) & Percentage (\%) & p-values \\
\hline Number of pregnancies & $1.2 \pm 0.4$ & & $<0.0001$ \\
Mean & 47 & 78.3 & \\
1 & 13 & 21.7 & \\
2 & & & \\
Age of first pregnancy & $15.97 \pm 2.5$ & & \\
Mean & 6 & 10.0 & \\
$10-14$ & 54 & 90.0 & \\
$15-19$ & & & \\
How old was your partner & $16 \pm 2.7$ & \\
Mean & $15-31$ & & \\
Range & & & \\
\hline
\end{tabular}

${ }^{*}$ Confidence level $=95 \%$; Critical value $=1.96$; and Level of significance $=0.05$. 


\subsection{Consequences of Teenage Pregnancy}

\subsubsection{Educational Consequences}

A total of $35(58.3 \%)$ participants were in school at the time of the pregnancy and out of this number $21(60.0 \%)$ dropped out from school as a result of their pregnancy (Table 6).

\subsubsection{Health Consequences}

A little below one third, 18 (30.0\%) of the participants reported health problems they faced as a direct effect of pregnancy. These include: anaemia in pregnancy, $6(10.0 \%)$, severe malaria, 4 (6.0\%), pregnancy induced hypertension, $3(5.0 \%)$, prolonged labor, 3 (5.0\%) and psychological trauma, 2 (3.3\%) (Table 6).

\subsubsection{Emotional and Psychological Consequences}

Psychologically and emotionally, 40 (66.7\%) respondents regretted being pregnant at this stage of their life (Table 7). From the total of 60 respondents, 11

Table 6. Consequences of teenage pregnancy.

\begin{tabular}{|c|c|c|c|}
\hline Study Parameter & Frequency (n) & Percentage (\%) & $\mathrm{p}$-values \\
\hline In school when you got pregnant & & & 0.1967 \\
\hline Yes & 35 & 58.3 & \\
\hline No & 25 & 41.7 & \\
\hline Dropped out of school & & & 0.2367 \\
\hline Yes & 21 & 60.0 & \\
\hline No & 14 & 40.0 & \\
\hline $\begin{array}{l}\text { Intend to or are you back at } \\
\text { school }\end{array}$ & & & 0.0045 \\
\hline Yes & 41 & 68.3 & \\
\hline No & 19 & 31.7 & \\
\hline $\begin{array}{l}\text { Working or learning a trade } \\
\text { when you got pregnant }\end{array}$ & & & 0.0098 \\
\hline Yes & 20 & 33.3 & \\
\hline No & 40 & 66.7 & \\
\hline $\begin{array}{l}\text { Any health problems in your } \\
\text { pregnancy }\end{array}$ & & & 0.0020 \\
\hline Yes & 18 & 30.0 & \\
\hline No & 42 & 70.0 & \\
\hline Your child frequently fell sick & & & 0.3017 \\
\hline Yes & 26 & 43.3 & \\
\hline No & 34 & 56.7 & \\
\hline $\begin{array}{l}\text { Regretted being pregnant at } \\
\text { this age }\end{array}$ & & & 0.0098 \\
\hline Yes & 40 & 66.7 & \\
\hline No & 20 & 33.3 & \\
\hline
\end{tabular}

${ }^{*}$ Confidence level $=95 \%$; Critical value $=1.96$; and Level of significance $=0.05$. 
Table 7. Emotional reactions to the pregnancy.

\begin{tabular}{lcc}
\hline \multicolumn{1}{c}{ Study Parameter } & Frequency (n) & Percentage (\%) \\
\hline $\begin{array}{l}\text { How did you react to the news of your } \\
\text { pregnancy }\end{array}$ & 11 & \\
Happy & 24 & 18.3 \\
Afraid & 13 & 40.0 \\
Disappointed & 6 & 21.7 \\
Felt Matured & 6 & 10.0 \\
Others & & 10.0 \\
How did your parents or guardians react to & & \\
the news of your pregnancy? & 8 & 13.3 \\
Happy & 19 & 31.7 \\
Afraid & 27 & 45.0 \\
Disappointed & 6 & 10.0 \\
Indifferent & 0 & 0 \\
Others & 11 & 18.3 \\
How did your partner react upon hearing? & & 3.3 \\
about your pregnancy? & & \\
Happy & 14 & 23.3 \\
Angry & & 16.7 \\
Accepted Responsibility & 23.3 \\
Denied Responsibility & & \\
Others & & \\
\hline
\end{tabular}

(18.3\%) said they were happy at confirming their pregnancy, with $24(40.0 \%)$ saying they were frightened. Very few, 6 (10.0\%) felt matured (Table 7).

\subsubsection{Reaction of Parents/Guardians}

For most of the respondents, 27 (45.0\%), the parents were disappointed, followed by those who parents were frightened by the news, 19 (31.7\%) (Table 7).

\subsubsection{Reaction of Male Partners}

In the case of the male partners, 23 (38.3\%) accepted responsibility for the pregnancy, 14 (23.3\%) were happy, and 11 (18.3\%) denied responsibility (Table 7).

\section{Discussion}

Obstetric data available at the West Gonja Municipal health directorate covering the period $1^{\text {st }}$ January, 2016 to $31^{\text {st }}$ December, 2020; suggested a rising trend in Teenage pregnancy within the Municipality, and this is thus of major public health concern to the health authorities. This situation is not limited to the West Gonja Municipal, but across the globe [25] [26]. Certain factors have been identified in developing countries as driving forces [26]. For instance, a previous study in South Asia, found rising trend in teenage pregnancies to be associated with family structures, cultural practices, low socio-economic status, and low 
educational level of the victims [26].

The current study conducted in the West Gonja Municipality found that $55.0 \%$ of the study population were junior high school graduates or dropouts, while $8.3 \%$ and $16.7 \%$ had either no formal education or have completed primary school. These findings are in accordance with previous studies conducted in South Asia [26], Uganda [27] and Ghana [28]. The Ugandan study found that teenagers with no formal education had $30.0 \%$ chance of becoming pregnant, compared to $18.3 \%$ among those who were highly educated [27]. Again, the Ghanaian study reported that, teenagers who failed to complete junior high school or were undergoing apprenticeship or became unemployed after dropping out from school had a greater risk of becoming pregnant [28].

In this current study, cultural and family related factors, early marriage, lack of sexual and reproductive communication with parents and the limitation of the girl's right to determine and deal with her own reproductive interest were identified as major contributors to the rising trends in teenage pregnancy within the study area. These findings are in line with those reported in previous studies in other parts of Africa and also in Ghana [28] [29]. For instance, the current study results indicated that a great majority of the participants had difficulty discussing sexual and reproductive health issues with their parents, particularly their fathers. A study in Bolgatanga in the upper east region of Ghana, by Krugu et al., in 2017, reported that sexual communication/education was conspicuously absent in most homes of their study population [29].

Regarding socioeconomic factors as determinants of teenage pregnancy, the current study found that $30.0 \%$ of the teenage mothers were of low economic status while the remaining $70.0 \%$ belong to the middle-income class. This is similar to what was reported in a Ugandan study, were $30.0 \%$ of their study population were within the poorest socioeconomic class [27]. A study in South Asia reported higher teenage pregnancy rates of $52.0 \%$ in the lower social classes [26], much higher than that reported in the current study within the Savannah region of Ghana.

Examining the sexual behaviour of the participants, the mean age at which participants had their coitarche was $14.3 \pm 2.7$ years, and many (65.0\%) were initiated by their boyfriends. This is consistent with the mean age of $14.9 \pm 51.73$ years reported by Durowade et al., study in Ido-Ekiti in Nigeria [30].

The mode of initiation of sexual intercourse was consensual in about $55.0 \%$ of the cases while $30 \%$ of the participants were persuaded or coerced into the act. This disagrees with findings in a study conducted within a suburb of Accra Ghana, by Ankomah et al., who reported that $50 \%$ of the participants became pregnant through transactional sex to make some income, and that $20 \%$ were impregnated through sexual violence and exploitation [28]. In our opinion the disparity is due to the fact that Accra is a more cosmopolitan and commercial city, where a lot of teenagers migrate to, in search of greener pastures. Most of these teenage girls often have to settle for menial jobs on which they can barely survive on and eventually become vulnerable to transactional sex, and sexual 
abuse due.

A third of the teenage mothers in this study reported a health condition complicating their pregnancy. These conditions in descending order were: anaemia in pregnancy, hypertension in pregnancy, prolonged labour, and other labour and delivery associated complications. These findings differ Mann et al., study in South Australia who found health conditions complicating teenage pregnancy as mental health disorders and sexually transmitted diseases [5]. The findings of the current study however, are in line with Raj et al., study in South Asia [26]. They found medical conditions complication teenage pregnancy as: anaemia in pregnancy, pregnancy induced hypertension, preterm labour and spontaneous abortion, in descending order [26].

Closed to half of the parents were disappointed in their girl for getting pregnant, on the other hand, $38.3 \%$ of male partners accepted responsibility for the pregnancy. Our findings are in accordance with those of Ankomah et al., study in Ghana [28]. They reported that most parents/guardians were very unhappy, and in some cases highly disappointed in their daughters [28].

Furthermore, the current study assessed the reaction and psychological status of the teenage mothers to their own pregnancy. The current study found that, many $(40.0 \%)$ of the pregnant teenagers were afraid as they feared their parents react to the pregnancy and fact that their education, growth and development. This is similar to what was reported by Ankomah et al., in 2013 [28].

The current study in the Savannah region of Ghana, found many (60.0\%) of the teenage mother have used a form of contraceptive during their first sexual encounter, particularly the male condom. It was however noted that, as these girls had more sexual experience, most abandoned use of these contraceptives, a behaviour similarly reported in previous studies [31] [32]. For instance, Manning et al., reported that $69.0 \%$ of respondents used some form of contraception during their first sexual intercourse and approximately $75.0 \%$ of that group used the male condom [32].

The current study identified the following; school dropout, low self-esteem, unemployment and early parenthood as the major effects of teenage pregnancy on the teenage mothers. These findings are similar to those reported by studies conducted in South Asia [5], Ghana [33] and Nigeria [34]. Furthermore, the current study results indicated that $60.0 \%$ of their participants had to drop out of school due to pregnancy. Again, this study finding correlates with a similar study conducted in the Upper Denkyira West District of Ghana by Adu-gyamfi, who reported $96.3 \%$ dropout rate as a result of pregnancy [33]. Furthermore, in the current study, $68.3 \%$ of the teenage mothers had the intention returning to school when given the choice. However, in the Upper Denkyira West study, 93.8\% said they did not see any prospects of returning to school [33].

\section{Conclusion}

The current study identified the factors contributing to the rising trend of tee- 
nage pregnancy in the West Gonja Municipal as; low socio-economic status, family and culture related factors; communication barriers between parents and teenage girls particularly on sexual education, early marriage, low level of formal education, inadequate sexual and reproductive health knowledge and unsafe sexual behaviours of the teenagers.

\section{Limitations of the Study}

Transportation and inadequate finances were our main challenges as the subdistricts were sparsely distributed.

\section{Recommendations}

1) The West Gonja municipal heath directorate should initiate and lead a focused municipal health team targeted at reducing the prevalence of teenage pregnancy in the municipal.

2) The West Gonja Municipal Hospital should establish and maintain an adolescent health corner for discussion adolescent's reproductive health.

3) Parents/guardians should create an enabling environment at home to comfortably discuss sexual and reproductive health issues with their children, especially the female teenagers.

4) Traditional leaders should review and amend the old-age traditions which directly or indirectly suppress the girls' rights to decide her own educational, sexual and reproductive wishes.

5) Female teenagers should be encouraged to seek mentorship and guidance from people within their locality who have attained good reputation in the community.

\section{Acknowledgements}

We duly acknowledge the staff of the West Gonja Municipal Health Directorate, The West Gonja Hospital and the department of Community Health of the University for Development Studies for their support guidance.

\section{Funding}

The project was fully self-financed.

\section{Ethical Consideration}

Ethical clearance was obtained from the West Gonja Municipal Health Directorate before the research commenced. The participants gave their consent before they were recruited into the research. The participants were not coerced to take part in the study. The whole study including the methodology, the benefit of the study, the harm involved and the voluntary aspect were made known to the participants to aid them in making informed decision. Participants were assured of confidentiality and anonymity. Participants were informed that there were no incentives and that they could withdraw at any time during the study. They were 
also assured of no or minimal harm both physically and mentally during participation.

\section{Authors Contribution}

N. J., W. S. F., S. V., K. P. formulated the idea, collected the data and analysed.

D. E. M. read through the introduction, analysed data, discussion and approved the manuscript for publication.

\section{Conflicts of Interest}

There was no conflict of interest.

\section{References}

[1] Sedgh, G., Sc, D., Finer, L.B., Bankole, A., et al. (2015) Adolescent Pregnancy, Birth, and Abortion Rates across Countries: Levels and Recent Trends. Journal of Adolescent Health, 56, 223-230. https://doi.org/10.1016/j.jadohealth.2014.09.007

[2] Kassa, G.M., Arowojolu, A.O., Odukogbe, A.A., et al. (2018) Prevalence and Determinants of Adolescent Pregnancy in Africa: A Systematic Review and Meta-Analysis. Reproductive Health, 15, 195. https://doi.org/10.1186/s12978-018-0640-2

[3] WHO (2014) Adolescent Pregnancy Fact Sheet. Adolescents Pregnancy Fact Sheet. https://www.who.int/news-room/fact-sheets/detail/adolescent-pregnancy

[4] WHO (2004) Adolescent Pregnancy. Geneva.

[5] Mann, L., Bateson, D. and Black, K.I. (2020) Teenage Pregnancy. Australian Journal of General Practice, 49, 310-316. https://doi.org/10.31128/AJGP-02-20-5224

[6] Yussif, A.S., Lassey, A., Ganyaglo, G.Y., et al. (2017) The Long-Term Effects of Adolescent Pregnancies in a Community in Northern Ghana on Subsequent Pregnancies and Births of the Young Mothers. Reproductive Health, 14, 178. https://doi.org/10.1186/s12978-017-0443-X

[7] Abbas, A.M., Ali, S.S., Ali, M.K. and Fouly, H. (2017) The Maternal and Neonatal Outcomes of Teenage Pregnancy in a Tertiary University Hospital in Egypt. Proceedings in Obstetrics and Gynecology, 7, 1-10. https://doi.org/10.17077/2154-4751.1350

[8] Asare, B.Y.A., Baafi, D., Dwumfour-Asare, B. and Adam, A.R. (2019) Factors Associated with Adolescent Pregnancy in the Sunyani Municipality of Ghana. International Journal of Africa Nursing Sciences, 10, 87-91. https://doi.org/10.1016/j.ijans.2019.02.001

[9] Bissell, M. (2000) Socio-Economic Outcomes of Teen Pregnancy and Parenthood: A Review of the Literature. Canadian Journal of Human Sexuality, 9, 191-204.

[10] Aviisah, P.A., Dery, S., Atsu, B.K., Yawson, A., Alotaibi, R.M., Rezk, H.R., et al. (2018) Modern Contraceptive Use among Women of Reproductive Age in Ghana: Analysis of the 2003-2014 Ghana Demographic and Health Surveys. BMC Women's Health, 18, Article 141. https://doi.org/10.1186/s12905-018-0634-9

[11] Darroch, J.E., Sedgh, G. and Ball, H. (2011) Contraceptive Technologies: Responding to Women's Needs. Guttmacher Institute, New York.

[12] Odimegwu, C. and Mkwananzi, S. (2016) Factors Associated with Teen Pregnancy in Sub-Saharan Africa: A Multi-Country Cross-Sectional Study. African Journal of Reproductive Health, 20, 94-107. https://doi.org/10.29063/ajrh2016/v20i3.14

[13] Ghana Statistical Service (GSS) (2010) Population \& Housing Census National 
Analytical Report. 1-91.

[14] Azevedo, W.F., Diniz, M.B., Fonseca, E.S., Azevedo, L.M. and Evangelista, C.B. (2015) Complications in Adolescent Pregnancy: Systematic Review of the Literature. Einstein (Sao Paulo), 13, 618-626. https://doi.org/10.1590/S1679-45082015RW3127

[15] Manning, W.D., Longmore, M.A. and Giordano, P.C. (2000) The Relationship Context of Contraceptive Use at First Intercourse. Family Planning Perspectives, 32, 104-110. https://doi.org/10.2307/2648158

[16] Adu-gyamfi, E. (2014) Assessing the Effect of Teenage Pregnancy on Achieving Universal Basic Education in Ghana: A Case Study of Upper Denkyira West District. Journal of Education and Practice, 5, 46-60.

[17] Maliki, A.E. (2012) The Effect of Teenage Pregnancy on Adolescents in Amassoma Community of Southern Ijaw Local Government Area of Bayelsa State. Asian Social Science, 8, 62-66. https://doi.org/10.5539/ass.v8n1p62

[18] Der, E.M., Sutaa, F., Azongo, T.B. and Kubio, C. (2016) Stillbirths at the West Gonja Hospital in Northern Ghana. Journal of Medical and Biomedical Sciences, 5, 1-7. https://doi.org/10.4314/jmbs.v5i1.1

[19] Fraenkel, J.R. and Wallen, N.E. (2000) How to Design and Evaluate Research in Education. 2nd Edition, McGraw Hill Inc., Boston.

[20] Bordens, K.S. and Abbott, B.B. (2002) Research Design and Methods: A Process Approach. 5th Edition, McGraw-Hill Companies, New York.

[21] Fink, A. (2001) How to Sample in Survey. Sage Publications Inc., New York.

[22] Sarantokos, S. (1998) Social Research. Palgrave Macmillan Ltd., London.

[23] Megel, M.E. and Heermann, J.A. (1994) Methods of Data Collection. Plastic Surgical Nursing, 14, 109-110. https://doi.org/10.1097/00006527-199406000-00014

[24] Córdova, A. (2009) Americas Barometer Insight Series No. 6: Methodological Note: Measuring Relative Wealth Using Household Asset Indicators. 1-9.

[25] Ahinkorah, B.O., Hagan, J.E., Seidu, A.A., Budu, E., Hormenu, T., Mintah, J.K., et al. (2019) Access to Adolescent Pregnancy Prevention Information and Services in Ghana: A Community-Based Case-Control Study. Front Public Health, 7, 382. https://doi.org/10.3389/fpubh.2019.00382

[26] Raj, A.D., Rabi, B., Amudha, P., van Teijlingen Edwin, R. and Glyn, C. (2010) Factors Associated with Teenage Pregnancy in South Asia: A Systematic Review. Health Science Journals, 4, 3-14.

[27] Gideon, R. (2013) Factors Associated with Adolescent Pregnancy and Fertility in Uganda: Analysis of the 2011 Demographic and Health Survey Data. American Journal of Sociological Research, 3, 30-35. https://doi.org/10.11648/j.ss.20130201.12

[28] Ankomah, A. and Gyesaw, K. (2013) Experiences of Pregnancy and Motherhood among Teenage Mothers in a Suburb of Accra, Ghana: A Qualitative Study. International Journal of Women's Health, 5, 773-780. https://doi.org/10.2147/IJWH.S51528

[29] Krugu, J.K., Mevissen, F., Münkel, M. and Ruiter, R. (2017) Beyond Love: A Qualitative Analysis of Factors Associated with Teenage Pregnancy among Young Women with Pregnancy Experience in Bolgatanga, Ghana. Culture, Health \& Sexuality, 19, 293-307. https://doi.org/10.1080/13691058.2016.1216167

[30] Adetokunbo, S., Olomofe, C.O., Fawole, A.A., Adebola, O.E. and Olaniyan, T.O. (2017) Early Sexual Debut: Prevalence and Risk Factors among Secondary School Students in Ido-ekiti, Ekiti State, South-West Nigeria. African Health Sciences, 17, 614-622. https://doi.org/10.4314/ahs.v17i3.3 
[31] Pearson, V.A., Owen, M.R., Phillips, D.R., Gray, D.J. and Marshall, M.N. (1995) Teenage Pregnancy: A Comparative Study of Teenagers Choosing Termination of Pregnancy or Antenatal Care. Journal of the Royal Society of Medicine, 88, 384-388.

[32] Lexander, C.S. and Guyer, B. (1993) Adolescent Pregnancy: Occurrence and Consequences. Pediatric Annals, 22, 85-88. https://doi.org/10.3928/0090-4481-19930201-05

[33] Woodward, V.M. (1995) Psychosocial Factors Influencing Teenage Sexual Activity, Use of Contraception and Unplanned Pregnancy. Midwifery, 11, 210-216. https://doi.org/10.1016/0266-6138(95)90006-3

[34] Orji, E.O. and Esimai, O.A. (2005) Sexual Behaviour and Contraceptive Use among Secondary School Students in Ilesha South West Nigeria. Journal of Obstetrics and Gynaecology, 25, 269-272. https://doi.org/10.1080/01443610500107395 